\title{
Advances in Clinical Application of ctDNA Detection in NSCLC \\ ${ }^{1}$ Kang Qin, ${ }^{2}$ Helei Hou and ${ }^{3}$ Xiaochun Zhang* \\ 1,2,3*Department of Medical Oncology, The Affiliated Hospital of Qingdao University, Qingdao University, 16 Jiangsu Road, Qingdao, 266003, China
}

Article Info

\section{Article Notes}

Received: January 04, 2018

Accepted: March 28, 2018

\section{${ }^{*}$ Correspondence:}

Dr. Xiaochun Zhang

Department of Medical Oncology, The Affiliated Hospital of Qingdao University, Qingdao University, 16 Jiangsu Road, Qingdao, 266003, China; Telephone: 086053282913271;

Fax: 086053282913271 ,

E-mail: zhangxiaochun9670@126.com

(c) 2018 Zhang $X$. This article is distributed under the terms of the Creative Commons Attribution 4.0 International License.

\section{ABSTRACT}

With high morbidity and mortality, lung cancer has become the leading cause of cancer-related death worldwide, of which $85 \%$ are non-small-cell lung cancer (NSCLC). Most patients present with advanced disease at diagnosis and 5 -year survival rate is no more than $30 \%$ due to lack of appropriate screening and early detection. In spite of tissue samples, ctDNA (circulating tumor DNA) is also widely used for molecular profiling to guide the treatment of NSCLC for lots of advantages. This review mainly focuses on the clinical and investigational applications of ctDNA detection in facilitating the personalized therapy of NSCLC.

Initially reported by Mandel et al. in $1948^{1}$, cfDNA (cell-free DNA) refers to the acellular, free DNA fragments in circulation (plasma or serum) derived from somatic cells through mechanisms like necrosis, apoptosis and exosome secretion. ctDNA is cfDNA generated by tumor cells, which carries cancerassociated genetic alterations ${ }^{2,3}$. In 1977, Leon et al. first reported that the level of plasma ctDNA of patients with cancer was significantly higher than that of normal persons ${ }^{4}$, which was also confirmed in NSCLC ${ }^{5,6}$. In NSCLC patients, techniques for targetable genetic ctDNA detection have improved from traditional ARMS, HPLC, BEAMing, FISH to new generations of NGS (next generation sequencing), ddPCR and CAPP-Seq etc. Compared with traditional detection methods, NGS shows extraordinary advantages like massively parallel sequencing, lower-inputs, cost-effectivity, ultra-sensitivity and hyper accuracy ${ }^{7,8}$. The main applications of ctDNA detection in the personalized treatment of NSCLC patients will be discussed in this review.

\section{Clinical application of ctDNA detection in NSCLC}

\section{Identification of targetable genetic alterations}

Targetable genetic alterations in NSCLC patients for which multiplex sequencing is recommended by NCCN (National Comprehensive Cancer Network) guidelines include: EGFR mutations, ALK fusions, MET exon 14 skipping mutations, BRAF mutations, HER2 (ERBB2) amplification and indels, ROS1 and RET fusions ${ }^{9}$. Multiple studies have confirmed that it was reliable to detect targetable EGFR mutations, either single hot-spot gene detection (Table 1) $)^{10-18}$ or multiplex-parallel targetable genetic sequencing (Table 2) ${ }^{19-24}$ through various platforms with high sensitivity and specificity. Remarkably, NGS-based detection and ddPCR show outstandingly high diagnostic value for the classic Del19, L858R, T790M mutation(Table1), indicating that ctDNA sequencing, especially the ultra-sensitive NGS-based sequencing could guide TKIs treatment directly. Moreover, ctDNA detection, especially the massively parallel NGS, plays a critical role in disclosing novel targetable mutations. For instance, in the study by Cui et al., 2 rare 
Table1. EGFR mutations identified by different ctDNA sequencing platforms in NSCLC patients.

\begin{tabular}{|c|c|c|c|c|c|c|c|}
\hline \multirow{2}{*}{ Method } & \multirow{2}{*}{ Sample } & Positivity & Sensitivity & Specificity & Concordance & \multirow{2}{*}{ PPV $^{\mathbf{a}}$} & \multirow{2}{*}{ Ref } \\
\hline & & (\%) & (\%) & (\%) & (\%) & & \\
\hline $\mathrm{ARMS}^{\mathrm{b}}$ & plasma & 10.5 & 65.7 & 99.8 & 94.3 & - & [10] \\
\hline ME-PCR ${ }^{c}$ & plasma & 49.3 & 100 & 90 & 94.4 & - & [11] \\
\hline PNA-PCR ${ }^{d}$ & plasma & 15 & 17.1 & 100 & 27.5 & - & [12] \\
\hline $\mathrm{DHPLC}^{\mathrm{e}}$ & plasma & 34.3 & 81.8 & 89.5 & 74 & - & [13] \\
\hline ARMS & plasma & 16.7 & 75 & 97.1 & 92.9 & - & [14] \\
\hline $\begin{array}{c}\text { cobas }^{\circledR} \text { EGFR } \\
\text { test }\end{array}$ & plasma & 11.7 & 60.7 & 96.4 & 91.3 & - & [15] \\
\hline \multirow{6}{*}{$\mathrm{NGS}^{f}$} & \multirow{6}{*}{ plasma } & \multirow{6}{*}{-} & 87 & 96 & \multirow{6}{*}{-} & \multirow{6}{*}{-} & \multirow{6}{*}{16} \\
\hline & & & (del19) & (del19) & & & \\
\hline & & & 100 & 100 & & & \\
\hline & & & (L858R) & (L858R) & & & \\
\hline & & & 93 & 94 & & & \\
\hline & & & (T790M) & (T790M) & & & \\
\hline Deep & \multirow{4}{*}{ plasma } & \multirow{4}{*}{-} & 50.9 & 98 & \multirow{4}{*}{-} & \multirow{4}{*}{-} & \multirow{4}{*}{ [17] } \\
\hline Sequen- & & & (del19) & (del19) & & & \\
\hline \multirow[t]{2}{*}{ cing } & & & 51.9 & 94.1 & & & \\
\hline & & & (L858R) & (L858R) & & & \\
\hline \multirow{6}{*}{$d d P C R^{f}$} & \multirow{6}{*}{-} & \multirow{6}{*}{-} & 82 & \multirow{6}{*}{-} & \multirow{6}{*}{-} & 100 & \multirow{6}{*}[18]{} \\
\hline & & & (del19) & & & (del19) & \\
\hline & & & 74 & & & 100 & \\
\hline & & & (L858R) & & & (L858R) & \\
\hline & & & 77 & & & 79 & \\
\hline & & & (T790M) & & & (T790M) & \\
\hline
\end{tabular}

Note: Abbreviations

PPVa: positive predicitve value

ARMS $^{\text {b }}$ : Amplifcation Refractory Mutation System

ME-PCR': mutant-enriched polymerase chain reaction (PCR)

PNA-PCR : peptide nucleic acid polymerase chain reaction

DHPLC : denaturing high-performance liquid chromatography

ddPCR : droplet digital PCR

fusion types including FAM179A-ALK and COL25A1-ALK were identified in addition to the most common EML4-ALK fusion $^{20}$. The previous study of our team also confirmed that apart from common targeted mutations, other less common genomic alterations of which the targeted agents are still under clinical research (such as mTOR inhibitors, PARP inhibitors, and CDK4/6 inhibitors) are found as well by hybrid capture-based 508-gene panel NGS assay (Oseq-NT) ${ }^{25}$. More importantly, ctDNA analysis could reveal the genetic alterations which are missed by the tissue detection ${ }^{24,26}$.

\section{Response assessment by dynamic monitoring of ctDNA}

The non-invasiveness, repeatability of liquid biopsy as well as short half-life (16 minutes 2.5 hours) ${ }^{27}$ of ctDNA all together enable the utility of ctDNA detection as one way to dynamically monitor response to TKIs. It was suggested that the dropping degree to which the EGFR mutation level in urine and plasma ctDNA was indicative of response to TKIs $^{16,28,29}$. By dynamically monitoring the level of EGFR mutations in plasma ctDNA with PCR test and ultra-deep
NGS, an average percent decrease of $63.5 \%$ were observed after 14 days of treatment, and in all but two patients, mutation clearing time was no more than 60 days $^{30}$. Kim et al reported that 10 cases of EGFR-activating mutation in ctDNA detected by PNA-mediated PCR clamping were found disappear in plasma after TKIs treatment for 2 months ${ }^{12}$. In Imamura F et al.'s study, complete disappearance of major EGFR ctDNA was observed in57.1\% patients after 15 days of TKIs treatment ${ }^{31}$.

In NSCLC, ctDNA level could also be used as a prognostic biomarker. NSCLC patients with higher circulating EGFR copy number levels had a lower OS and PFS, and those who with high levels of EGFR-activating mutations in plasma samples had longer OS and PFS upon TKIs treatment ${ }^{32,33,34}$. In addition, meta-analysis by Fan $\mathrm{G}$ et al. also verified that patients with detectable KRAS mutations in plasma ctDNA have a significantly shorter OS and/or PFS compared to patients with wild-type $\mathrm{KRAS}^{34}$.

\section{Disclosing novel mechanisms of TKIs resistance}

Mechanisms of resistance after failure from prior TKIs 
Table 2. Targetable ctDNA alterations detected by multiplex NGS assay in NSCLCpatients.

\begin{tabular}{|c|c|c|c|c|c|c|c|}
\hline Method & $\begin{array}{l}\text { Targetable genetic } \\
\text { alteration }\end{array}$ & $\begin{array}{c}\text { Sensitivity } \\
\text { (\%) }\end{array}$ & $\begin{array}{l}\text { Positivity } \\
\text { (\%) }\end{array}$ & $\begin{array}{l}\text { Specificity } \\
\text { (\%) }\end{array}$ & $\begin{array}{l}\text { Accuracy } \\
\text { (\%) }\end{array}$ & $\begin{array}{c}\text { Concordance } \\
\text { (\%) }\end{array}$ & Ref \\
\hline Capture based NGS & ALK fusion/rearrangement & 79.2 & - & 100 & - & - & [19] \\
\hline Capture based NGS & ALK fusion & 54.2 & - & 100 & 71.8 & - & {$[20]$} \\
\hline Guardant 360 based NGS & ALK SNVs $/$ fusions & - & 6 & - & - & - & [21] \\
\hline $\begin{array}{l}\text { Multiple sequencing } \\
\text { techniques }\end{array}$ & $\begin{array}{l}\text { EGFR, } \\
\text { KRAS, } \\
\text { TP53, } \\
\text { BRAF, } \\
\text { PIK3CA, } \\
\text { ERBB2 }\end{array}$ & 69.2 & - & 93.3 & $\begin{array}{c}94.7 \\
\left(\mathrm{PPV}^{b}\right)\end{array}$ & 78.1 & {$[22]$} \\
\hline $\begin{array}{l}\text { NGS } \\
\text { IonTorrent } \\
\text { PGM platform }\end{array}$ & $\begin{array}{l}\text { EGFR, } \\
\text { KRAS, } \\
\text { BRAF, } \\
\text { ERBB2, } \\
\text { PI3KCA }\end{array}$ & 58 & - & 87 & - & - & {$[23]$} \\
\hline $\begin{array}{l}\text { Biascorrected } \\
\text { targeted NGS }\end{array}$ & $\begin{array}{c}\text { EGFR, } \\
\text { ALK, } \\
\text { ROS1, } \\
\text { RET } \\
\text { HER2ins, } \\
\text { METamp }\end{array}$ & 77 & - & 100 & - & - & {$[24]$} \\
\hline
\end{tabular}

Note: Abbreviations

SNV : single nucleotide variant

PPV ${ }^{b}$ : positive predictive value

treatment in NSCLC patients are highly heterogeneous. Multiple studies have confirmed that ctDNA profiling is reliable in disclosing novel mechanisms of TKIs resistance. Through serial ctDNA monitoring, EGFR C797S was suggested to be one of the acquired resistant mechanisms of Osimertinib $^{35,36}$. Recently, novel C797G point mutation ${ }^{37}$ and EGFR-exon19del allele amplification ${ }^{38}$ were found to mediate resistance to Osimertinib through ctDNA testing in NSCLC patients. Several secondary point mutations in ALK were found in ALK positive NSCLC patients by comprehensive ctDNA assays at the presence of progression after treatment of crizotinib ${ }^{21}$. Although ctDNA detection is widely used in detecting resistant mutations in NSCLC patients, it was noteworthy that further tissue biopsy samples could discover mutations with low frequency and other rare resistance mechanisms like SCLC transformation ${ }^{38}$.

\section{Significance of ctDNA assay in NSCLC screening and early diagnosis}

It was suggested that ctDNA detection by NGS could be used for screening and early diagnosis NSCLC ${ }^{22}$. A DNA cutoff level of over $20 \mathrm{mg} / \mathrm{ml}$ could distinguish between lung cancer patients and healthy persons ${ }^{39}$. The ultrasensitive CAPP-Seq demonstrated a sensitivity of $50 \%$ in ctDNA detection for patients with stage I NSCLC ${ }^{40}$. Positive detection rates of plasma ctDNA detected by Sec-Seq (an NGS-based systematic error correction sequencing) in patients with stage I lung cancer was $85 \%{ }^{41}$, indicating that ctDNA detection is able to distinguish pulmonary malignancies and other benign diseases. The clinical utility of ctDNA detection for the screening and early diagnosis of NSCLC is limited due to the sensitivity of current sequencing technologies ${ }^{42}$. ctDNA assay may work better in early diagnosis of NSCLC when combined with other radiological strategies such as low-dose $\mathrm{CT}^{43}$.

\section{Tracking recurrence of NSCLC}

Studies show that levels of ctDNA were highly correlated with tumor volume and can be used in distinguishing between residual disease and treatment-related imaging changes $^{44}$. What's more, relapse identified by ctDNA detection was 70 days prior to CT scanning ${ }^{45}$. By profiling the ctDNA in postoperative plasma of the first 100 participants in TRACERx study through a tumor-specific phylogenetic approach, independent predictors of ctDNA release was identified and subclonal nature of lung cancer relapse and metastasis were tracked as well ${ }^{46}$. Another prospective study (NCT02965391) concentrating on the dynamic change and potential role of multiple ctDNA detection by cSMART in monitoring post-operative recurrence of patients with early stage NSCLC shows that 76.9\% (10/13) underwent drastic drop of ctDNA level, and ctDNA level of all patients decreased to $0 \% 72$ hours after surgery. No recurrence was identified by ctDNA detection 1 month post operation ${ }^{47}$. DARWIN II (NCT02314481) is a multiarm, non-randomized phase II study examining the effect of intratumor heterogeneity on the efficacy of anti-PDL1 immunotherapy in which relationship between intratumor heterogeneity and ctDNA will be examined, thus new ways of cancer screening and monitoring will promisingly be 
Table 3. The advantages and challenges of clinical utility of ctDNA detection in NSCLC.

\section{Advantages Challenges}

Easy and convenient to perform since ctDNA is mainly extracted Concentration of ctDNA is extremely low. Therefore both the sensitivity from blood or serum.

Non-invasive process of ctDNA collection allows for repeat examination. and specificity of detection need to be further improved.

Level of ctDNA changes dynamically thus represents a real-time biomarker for tumor diagnosis and monitoring. Lack of standardized methods for ctDNA detection, processing, analysis and statistic interpretation.

Useful in situations when tissue biopsy is not available or diagnosed as negatively mutated. Present mutational status of both primary mutations and /or metastatic clones, thus provide a cfDNA released by non-malignant cells could disturb analysis results of ctDNA detection. more fully capture of tumor heterogeneity.

explored ${ }^{48}$.But another emerging controversy is whether prompt actions should be taken as response to dynamic changes of ctDNA mutational status and how to modify treatment strategies accordingly. Results of the ongoing studies are worthy of expectation.

\section{Conclusions and Perspective}

In spite of lots of challenges (Table 3), we have witnessed the rapid improvements of ctDNA analysis in cancer diagnosis and treatment assessment in recent years. As the concentration of ctDNA is extremely low $(<1 \%)$, increasing the test sensitivity and specificity is a key point in promoting utility of ctDNA detection in diagnosis and treatment of cancer. What's more, consensus in standard for technique selection and statistic analysis should also be made to avoid discrepancies amongst different detecting processes. ctDNA detection is now playing a critical role in personalized treatment of NSCLC patients and has wide application prospect.

\section{Acknowledgement}

This work was supported by Taishan Scholar foundation (No.tshw201502061 to Xiaochun Zhang), Qingdao people's Livelihood Science and technology program (16-6-2-3-nsh to Xiaochun Zhang) and the second batch of Qingdao soft science project[16-9-2-1-(1)-CHX to Xiaochun Zhang].

\section{Conflict of Interest statement}

No potential conflicts of interest were disclosed.

\section{References}

1. Mandel P. Les acides nucleiques du plasma sanguin chez l'homme[J]. CR Acad Sci Paris. 1948; 142: 241-243.

2. Spellman P T, Gray JW. Detecting cancer by monitoring circulating tumor DNA[J]. Nat Med. 2014; 20(5): 474-475.

3. Fenizia F, De Luca A, Pasquale R, et al. EGFR mutations in lung cancer: from tissue testing to liquid biopsy[J]. Future Onco. 2015; 11(11): 1611-1623.

4. Leon SA, Shapiro B, Sklaroff DM, et al. Free DNA in the serum of cancer patients and the effect of therapy[J]. Cancer Res. 1977; 37(3): 646650.

5. Ulivi P, Mercatali L, Casoni GL, et al. Multiple marker detection in peripheral blood for NSCLC diagnosis[J]. PloS one. 2013; 8(2): e57401.
6. Szpechcinski A, Chorostowska-Wynimko J, Kupis W, et al. Quantitative analysis of free-circulating DNA in plasma of patients with resectable NSCLC[J]. Expert Opin Biol Ther. 2012; 12(sup1): S3-S9.

7. Liu S, Wang $\mathrm{H}$, Zhang $\mathrm{L}$, et al. Rapid detection of genetic mutations in individual breast cancer patients by next-generation DNA sequencing[J]. Hum Genomics. 2015; 9(1):1-10.

8. Luthra R, Chen H, Roy-Chowdhuri S, et al. Next-generation sequencing in clinical molecular diagnostics of cancer: advantages and challenges[J]. Cancers. 2015; 7(4): 2023-2036.

9. Ettinger DS, Wood DE, Akerley W, et al. Non-Small Cell Lung Cancer, Version 6.2015 Featured Updates to the NCCN Guidelines[J]. J Natl Compr Canc Netw. 2015; 13(5): 515-524.

10. Douillard JY, Ostoros G, Cobo M, et al. Gefitinib treatment in EGFR mutated caucasian NSCLC: circulating-free tumor DNA as a surrogate for determination of EGFR status[J]. J Thorac Oncol. 2014; 9(9): 1345-1353.

11. He C, Liu M, Zhou C, et al. Detection of epidermal growth factor receptor mutations in plasma by mutant-enriched PCR assay for prediction of the response to gefitinib in patients with non-small-cell lung cancer[J]. Int J Cancer. 2009; 125(10): 2393-2399.

12. Kim HR, Lee SY, Hyun DS, et al. Detection of EGFR mutations in circulating free DNA by PNA-mediated PCR clamping[J]. J Exp Clin Cancer Res. 2013; 32(1): 50.

13. Bai H, Mao L, Wang S, et al. Epidermal growth factor receptor mutations in plasma DNA samples predict tumor response in Chinese patients with stages IIIB to IV non-small-cell lung cancer[J]. J Clin Oncol. 2009; 27(16): 2653-2659.

14. Kimura H, Suminoe M, Kasahara K, et al. Evaluation of epidermal growth factor receptor mutation status in serum DNA as a predictor of response to gefitinib (IRESSA)[J]. Br J Cancer. 2007; 97(6): 778-784.

15. Weber B, Meldgaard P, Hager H, et al. Detection of EGFR mutations in plasma and biopsies from non-small cell lung cancer patients by allele-specific PCR assays[J]. BMC cancer. 2014; 14(1): 294.

16. Reckamp KL, Melnikova VO, Karlovich C, et al. A highly sensitive and quantitative test platform for detection of NSCLC EGFR mutations in urine and plasma[J]. J Thorac Oncol. 2016; 11(10): 1690-1700.

17. Uchida J, Kato K, Kukita Y, et al. Diagnostic accuracy of noninvasive genotyping of EGFR in lung cancer patients by deep sequencing of plasma cell-free DNA[J]. Clin Chem. 2015; 61(9): 1191-1196.

18. Sacher AG, Paweletz C, Dahlberg SE, et al. Prospective validation of rapid plasma genotyping for the detection of EGFR and KRAS mutations in advanced lung cancer[J]. JAMA Oncol. 2016; 2(8): 10141022.

19. Wang Y, Tian PW, Wang WY, et al. Noninvasive genotyping and monitoring of anaplastic lymphoma kinase (ALK) rearranged non-small cell lung cancer by capture-based next-generation sequencing[J]. Oncotarget. 2016; 7(40): 65208-65217. 
20. Cui S, Zhang W, Xiong L, et al. Use of capture-based next-generation sequencing to detect ALK fusion in plasma cell-free DNA of patients with non-small-cell lung cancer[J]. Oncotarget. 2017; 8(2): 27712780 .

21. Ihuegbu N, Banks KC, Fairclough SR, et al. Non-invasive detection of crizotinib resistance in ALK-rearranged lung adenocarcinoma directs treatment with next-generation ALK inhibitors[J]. J Clin Oncol. 2016; 34(suppl 15): abstr e20643.

22. Guo N, Lou F, Ma Y, et al. Circulating tumor DNA detection in lung cancer patients before and after surgery:[J]. SciRep. 2016; 6: 33519.

23. Couraud S, Paniagua FV, Villar S, et al. Non-invasive diagnosis of actionable mutations by deep sequencing of circulating-free DNA in non-small cell lung cancer: Findings from BioCAST / IFCT-1002 [J]. Clin Cancer Res. 2014; 20(17): 4613-4624.

24. Paweletz CP, Sacher AG, Raymond CK, et al. Bias-Corrected Targeted Next-Generation Sequencing for Rapid, Multiplexed Detection of Actionable Alterations in Cell-Free DNA from Advanced Lung Cancer Patients[J]. ClinCancer Res. An Official Journal of the American Association for Cancer Res. 2016; 22(4): 915-922.

25. Hou H, Yang X, Zhang J, et al. Discovery of targetable genetic alterations in advanced non-small cell lung cancer using a next-generation sequencing-based circulating tumor DNA assay[J]. Scientific Reports. 2017; 7(1): 14605.

26. Villaflor V, Won B, Nagy R, et al. Biopsy-free circulating tumor DNA assay identifies actionable mutations in lung cancer[J]. Oncotarget 2016; 7(41): 66880-66891.

27. Diehl F, Schmidt K, Choti MA, et al. Circulating mutant DNA to assess tumor dynamics[J]. Nat Med. 2008; 14(9): 985-990.

28. Karlovich CA, Goldman J, Sun JM, et al. Assessment of EGFR mutation status in matched plasma and tumor tissue of NSCLC patients from a phase 1 study of rociletinib (CO-1686).[J]. Clin Cancer Res An Official Journal of the American Association for Cancer Research. 2016; 22(10): 2386-2395.

29. Sorensen BS, Wu L, Wei W, et al. Monitoring of epidermal growth factor receptor tyrosine kinase inhibitor-sensitizing and resistance mutations in the plasma DNA of patients with advanced non-small cell lung cancer during treatment with erlotinib[J]. Cancer. 2014 120(24): 3896-3901.

30. Marchetti A, Palma JF, Felicioni L, et al. Early Prediction of Response to Tyrosine Kinase Inhibitors by Quantification of EGFR Mutations in Plasma of NSCLC Patients.[J]. J Thorac Oncol. 2015; 10(10): 14371443.

31. Imamura F, Uchida J, Kukita Y, et al. Early responses of EGFR circulating tumor DNA to EGFR tyrosine kinase inhibitors in lung cancer treatment[J]. Oncotarget. 2016; 7(44): 71782-71789.

32. Thompson JC, Yee SS, Troxel AB, et al. Detection of Therapeutically Targetable Driver and Resistance Mutations in Lung Cancer Patients by Next-Generation Sequencing of Cell-Free Circulating Tumor DNA[J]. ClinCancer Res An Official Journal of the American Association for Cancer Research. 2016; 22(23): 5772-5782.

33. Alegre E, Fusco JP, Restituto P, et al. Total and mutated EGFR quantification in cell-free DNA from non-small cell lung cancer patients detects tumor heterogeneity and presents prognostic value[J]. Tumour Biol, the Journal of the International Society for Oncodevelopmental Biology \& Medicine. 2016; 37(10): 13687-13694.

34. Fan G, Zhang K, Ding J, et al. Prognostic value of EGFR and KRAS in circulating tumor DNA in patients with advanced non-small cell lung cancer: a systematic review and meta-analysis[J]. Oncotarget. 2017; 8(20): 33922-33932.

35. Thress KS, Paweletz CP, Felip E, et al. Acquired EGFR C797S mutation mediates resistance to AZD9291 in non-small cell lung cancer harboring EGFR T790M[J]. Nat Med. 2015; 21(6): 560-562.

36. Wang S, Tsui ST, Liu C, et al. EGFR C797S mutation mediates resistance to third-generation inhibitors in T790M-positive non-small cell lung cancer[J]. J Hematol Oncol. 2016; 9(1): 59.

37. Menon R, Müller J, Schneider P, et al. A novel EGFRC797 variant detected in a pleural biopsy from an Osimertinib-treated patient using a comprehensive hybrid-capture based next-generation sequencing assay[J]. J Thorac Oncol. 2016; 11(9): e105-e107.

38. Minari R, Bordi P, Re MD, et al. Primary resistance to osimertinib due to SCLC transformation: issue of T790M determination on liquid rebiopsy[J]. Lung Cancer. 2018; 115: 21-27.

39. Catarino R, Coelho A, Arajo A, et al. Circulating DNA: Diagnostic Tool and Predictive Marker for Overall Survival of NSCLC Patients[J]. Plos One. 2012; 7(6): e38559.

40. Newman AM, Lovejoy AF, Klass DM, et al. Integrated digital error suppression for improved detection of circulating tumor DNA: [J]. Nat Biotechnol. 2016; 34(5): 547-555.

41. Tian G, Li X, Xie Y, et al. The Early Diagnosis in Lung Cancer by the Detection of Circulating Tumor DNA[J]. bio Rxiv. 2017; 189340

42. Chen KZ, Feng L, Fan Y, et al. Circulating Tumor DNA Detection in EarlyStage Non-Small Cell Lung Cancer Patients by Targeted Sequencing[J]. Sci Rep. 2016; 6: 31985.

43. Shu X, Huang CC, Min L, et al. Genomic variations in plasma cell free DNA differentiate early stage lung cancers from normal controls[J]. Lung Cancer. 2015; 90(1): 78-84.

44. Newman AM, Bratman SV, To J, et al. An ultrasensitive method for quantitating circulating tumor DNA with broad patient coverage. J NatMed. 2014; 20(5): 548-554.

45. Jamal-Hanjani M, Wilson GA, Mcgranahan N, et al. Tracking the Evolution of Non-Small-Cell Lung Cancer. J N Engl J Med. 2017; 376(22): 2109-2121.

46. Abbosh C, Birkbak NJ, Wilson GA, et al. Phylogenetic ctDNA analysis depicts early stage lung cancer evolution. J Nature. 2017; 545(7655): 446-451.

47. Wang J, et al.Clinical Trials.gov, Date of last update: December 3, 2017. Availablefrom:https://clinicaltrials.gov/ct2/results?cond=\&ter$\mathrm{m}=$ NCT02965391\&cntry $=\&$ state $=\&$ city $=\&$ dist $=$

48. Charles S, et al.Clincal Trials.gov, Date of last update: May 18, 2017 Available from:https://clinicaltrials.gov/ct2/results?cond=\&ter$\mathrm{m}=$ NCT $02314481 \&$ cntry $=\&$ state $=\&$ city $=\&$ dist $=$ 